\title{
ÁREA DE PROTEÇÃO AMBIENTAL (APA) DA BARRA GRANDE EM ICAPUÍ-CE: CAMINHOS PARA A SUSTENTABILIDADE
}

\author{
Antonio Jeovah de Andrade Meireles ${ }^{1}$, José Arimatea da Silva ${ }^{2}$, \\ WALLASON FARIAS DE SOUZA ${ }^{1}$ \\ ${ }^{1}$ Universidade Federal do Ceará (UFC) \\ Programa de Pós-Graduação em Geografia \\ ${ }^{2}$ Prefeitura Municipal de Icapuí \\ <meireles@ufc.br>, <j.arimateas12@gmail.com>. \\ $<$ wallason.farias@gmail.com>
}

DOI: $10.21439 /$ conexoes.v11i5.1352

\begin{abstract}
Resumo. O estuário Barra Grande, localizado no litoral de Icapuí, extremo Leste do Ceará, é composto por sistemas ambientais de extrema importância socioeconômica para o litoral cearense. Está inserido na diversidade de componentes geoambientais e ecológicos da planície costeira, tendo o ecossistema manguezal como síntese das conexões entre os componentes tipicamente costeiros (planície de maré, laguna, dunas, falésias e praias), com os marinhos (delta de maré e bancos de algas). O objetivo da pesquisa foi realizar zoneamento ambiental da Área de Proteção Ambiental (APA) da Barra Grande, envolvendo os sistemas ambientais adjacentes para aprimorar os instrumentos de gestão. A gestão foi proposta através de zoneamento ambiental a partir de diagnóstico e mapas temáticos. Foi possível constatar os impactos ambientais (principalmente os relacionados com a carcinicultura e indústria salineira), para a formulação das zonas de diversidade de usos, de conservação e de preservação. Como resultado, foi realizado diagnóstico geoambiental e proposta de zoneamento.
\end{abstract}

Palavras-chaves: Área de Proteção Ambiental (APA). Manguezal. Zoneamento. Gestão de UCs.

Abstract. The Barra Grande estuary, located in Icapuí coastline, extreme eastern Ceará, is composed of environmental systems of extreme socio-economic importance to the Ceará. It is inserted in the diversity of geoenvironmental and ecological components of the coastal plain, and the mangrove ecosystem as a synthesis of the connections between the typically coastal components (tidal flat, lagoon, dunes, cliffs and beaches), with marine (tidal delta and banks algae). The objective of the research was to carry out environmental zoning of the Environmental Protection Area (APA) of Barra Grande, involving the adjacent environmental systems to improve management tools. The management was proposed by environmental zoning from diagnosis and thematic maps. It was found environmental impacts (mainly related to shrimp farming and salt industry) for the formulation of the uses of diversity zones, conservation and preservation. As a result, it performed geoenvironmental diagnosis and zoning proposal.

Keywords: Environmental Protection Area (EPA). Mangrove. Zoning. Conservation Unit Management.

\section{INTRODUÇÃO}

A Unidade de Conservação (UC) inserida na planície costeira de Icapuí, extremo sudeste do litoral cearense e denominada de Área de Proteção Ambiental (APA) da Barra Grande foi criada em 12 de maio de 2000, através da Lei Municipal no 298/2000 (CEARÁ, 2000) e sua área original ampliada através da Lei 634/2014 (CEARÁ, 2014). Tal ampliação foi realizada de modo a incluir o banco de algas dos Cajuais na plataforma continental diante da desembocadura do canal estuarino perfazendo uma área total de 18.100 hectares localizada 
na porção central do município (Figura 11). Fazem parte da UC as comunidades de Barrinha à oeste, Placa e Berimbau ao leste, Cajuais e Icapuí-sede ao sul, ao Norte o Oceano Atlântico e as comunidades de Barra Grande e Requenguela. Os acessos são realizados por estradas vicinais desde o centro urbano de Icapuí ou através da rodovia estadual CE 261.

Figura 1: Mapa de localização do município e da área de estudo e os principais componentes geoambientais.

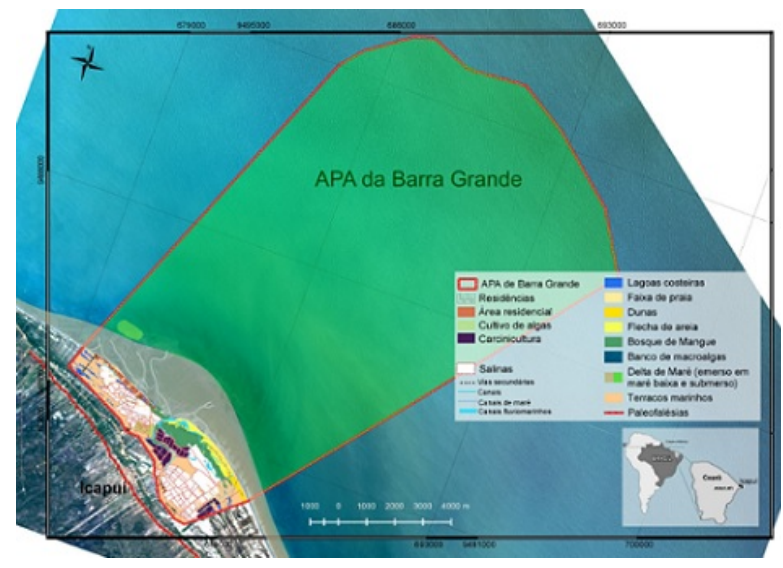

Fonte: Modificada de AQUASIS (2014).

As Áreas de Proteção Ambiental (APA) foram classificadas como "unidades de conservação de uso sustentável e definidas como uma área em geral extensa, com certo grau de ocupação humana, dotada de atributos abióticos, bióticos, estéticos ou culturais especialmente importantes para a qualidade de vida e o bemestar das populações humanas, e tem como objetivos básicos proteger a diversidade biológica, disciplinar o processo de ocupação e assegurar a sustentabilidade do uso dos recursos naturais" (BRASIL, 2000). A APA da Barra Grande foi instituída pelo poder executivo objetivando potencializar a gestão de sistema ambientais especiais e para a proteção dos ecossistemas diante das diversas formas de uso e ocupação em seu entorno.

Como elemento estruturador das ações de planejamento, gestão e para os distintos tipos de uso e ocupação da UC, foi possível constatar que o processo de institucionalização foi elaborado de modo a exigir a aplicação de métodos e técnicas apropriadas ao uso do solo, de maneira a proteger e recuperar os sistemas socioambientais delimitados pela UC. Foram evidenciadas as atividades de educação ambiental, principalmente aquelas relacionadas à Estação Ambiental Mangue Pequeno (EAMP) no desenvolvimento de práticas para dimensionar as atividades de controle social (desenvolvimento de uma consciência ecológica e conservacionista envolvendo a população local), e a recuperação do bosque de manguezal.

Os levantamentos geoambientais identificaram um conjunto de sistemas ambientais associados a depósitos geológicos de idade quaternária, cobertos por bosque de manguezal (com área aproximada de 136,6 ha), canais de maré, gamboas, terraços marinhos, flechas de areia (barras longitudinais) e, na sua extensão praial, um delta de maré (localmente denominado de banco de algas dos Cajuais) (MEIRELES; SANTOS, 2011) (ver figura 1).

As unidades morfológicas conectam-se ao estuário por meio dos fluxos de matéria e energia definidos no setor central da planície costeira e através das dinâmicas hidrológica e sedimentar relacionadas aos canais fluviomarinhos que conduzem a água doce (proveniente dos aquíferos dunar, do tabuleiro e da pluviometria) e salgada (flutuações semi-diurnas da maré). Nesse contexto de diversidade de componentes geológicos e geomorfológicos residem ecossistemas de elevada biodiversidade. Dispostos sobre esses vínculos geoambientais e ecodinâmicos estão as comunidades tradicionais de pescadores e marisqueiras em seus núcleos populacionais. Foi neste contexto ambiental que se delimitou a área de estudo. Desta forma, foi possível considerar a importância da APA da Barra Grande para a planície costeira desde as associações dos sistemas ambientais com as diversas formas de uso e ocupação.

Ao delimitar a UC e realizar a caraterização dos componentes geoambientais e socioeconômicos foi possível definir o objetivo principal da pesquisa: elaborar diagnóstico geoambiental enfatizando a definição de uma proposta de zoneamento ambiental. Dessa forma, orientar as ações de planejamento e gestão através de políticas públicas voltadas para melhorar a qualidade ambiental e de vida das populações envolvidas. Ao final, pretendeu-se constituir um conjunto de estratégicas para a conservação dos sistemas socioambientais e definir setores de preservação e recuperação do ecossistema manguezal.

\section{METODOLOGIA}

As atividades de pesquisa iniciaram com levantamentos dos procedimentos administrativos para a criação e ampliação da UC. Os procedimentos metodológicos para definir a dinâmica socioambiental e evolução dos processos costeiros foram relacionados com a caracterização dos indicadores geoambientais de mudanças do nível relativo do mar e os geossistemas e ecossistemas associados ao canal estuarino Barra Grande e à plataforma continental (delta de maré) (DIEGUES, 2001. 
QUEIROZ et al., 2013, MEIRELES, 2014a).

Com o embasamento bibliográfico, partiu-se para as atividades de campo com intuito de delimitar as unidades geoambientais, os usos e usuários, realizar as coletas de informações sobre o processo de ocupação e degradação do manguezal e do banco de algas dos Cajuais. Como síntese dos procedimentos relacionados com os aspectos geoambientais e ecodinâmicos foram elaborados os mapas geomorfológicos, uso e ocupação, impactos ambientais e de zoneamento do setor central da planície costeira. As atividades de campo se deram a partir de visitas em toda extensão da APA, demarcação do perímetro do bosque de mangue, das áreas degradadas e das em processo de recuperação (replantio de espécies de mangue em áreas degradadas pelas salinas e carcinicultura).

As atividades de gabinete, com os procedimentos de processamento de dados com a utilização de ferramentas de geoprocessamento, foram iniciadas com as análises das imagens de satélite como forma delimitação dos componentes geoambientais da APA. Através da utilização de imagens de satélite multitemporais e georreferenciadas com GPS geodésico foi possível delimitar os setores propostos para o zoneamento. A imagem de satélite utilizada como base para a definição das zonas foi WordView de 2 de abril de 2011 e disponibilizada pela Fundação Brasil Cidadão (FBC) através do Banco de Dados da Estação Ambiental Mangue Pequeno (EAMP) 1 Os dados brutos da imagem sofreram transformações através de técnicas de processamento digital de imagens (PDI), produzindo os primeiros elementos da base de dados para a produção de informações geoambientais. As etapas vinculadas ao PDI - pré-processamento, processamento de cores, realçamento de contraste, filtragem espacial, manipulações espectrais e classificação - facilitaram a identificação e a extração da informação contida nas imagens (principalmente quando relacionadas à cobertura vegetacional, os canais de maré, planícies hipersalinas, banco de algas e as diversidades de uso e ocupação). O software utilizado para o georreferenciamento e tratamento das imagens foram o QGis, adotando o sistema de projeção cartográfica UTM (Universal Transverso de Mercator) com o Datum WGS-84. Para o georreferenciamento da imagem de alta resolução WorldView 2, utilizadas para extração das informações geográficas de precisão, utilizou-se receptores geodésicos do sistema NAVSTAR GPS, com precisão nominal de $5 \mathrm{~mm}+1$

\footnotetext{
${ }^{1}$ Um importante banco de dados em ambiente SIG elaborado pelos técnicos do projeto De Olho na Água e, em parte, disponibilizados em $<w w w . d e o l h o n a a g u a . o r g . b r>$
}

ppm. Os dados foram processados em softwares do fabricante.

A evolução espaçotemporal (2002-2014) da linha de costa foi realizada por meio do software Digital Shoreline Analysis System (DSAS) versão 4.3, que é uma extensão do ArcGIS 10.1, elaborado pelo United States Geological Survey (USGS). Através de quatro procedimentos matemáticos e estatísticos fornecidos pelo DSAS, foi possível quantificar as variações máximas espaciais e temporais, a média de variação e a tendência de regressão linear para o período analisado.

A setorização de cada uma das zonas se deu com o agrupamento em zonas com características ambientais semelhantes (inicialmente definidas pela textura e padrões espectrais das imagens), considerando sua relevância ecológica, a dinâmica morfológica, o estágio de conservação ou degradação e usos e ocupação identificados. Desta forma, e com base no Sistema Nacional de Unidades de Conservação (SNUC), foi possível definir diversidades de setores para orientar as ações de planejamento e gestão da UC, inclusive com a delimitação de uma "Zona de Proteção Integral" e inserida na categoria de "Uso Sustentável".

Os critérios definidos para a proposta de zoneamento ambiental foram relacionados de acordo com a dinâmica atual dos sistemas ambientais vinculados aos distintos tipos de uso e ocupação, a necessidades de preservação de determinados setores para resguardar os resquícios de biodiversidade e a recuperação ambiental principalmente das áreas antes ocupadas pelo bosque de manguezal (Tabela 11):

Para a definição dos fluxos de matéria e energia, foram utilizados os componentes morfológicos da planície costeira, composição e classificação das estruturas sedimentares nos terraços marinhos, laguna e delta de maré e a direção preferencial das ondas, marés, ventos e hidrodinâmica estuarina.

Os termos sistema e unidades ambientais foram utilizados para evidenciar elementos espaciais (escala regional associado à planície costeira e localmente às unidades morfológicas cartografadas), representados pelos componentes geomorfológicos, interconectados através dos fluxos de matéria e energia e vinculados aos diversos usos e formas de ocupação distribuídos ao longo do litoral em estudo (MEIRELES; RUBIO, 1999, AQUASIS, 2014).

O mapa de zoneamento ambiental proposto está representado por duas zonas e seis setores. Foram espacializados de acordo com os indicadores geoambientais, os fluxos morfológicos e as relações socioeconômicos vinculadas às comunidades tradicionais e às de- 
Tabela 1: Indicadores geoambientais para a definição das zonas geoambientais da Área de Proteção Ambiental (APA) da Barra Grande.

\begin{tabular}{|c|c|c|}
\hline Indicadores & Classificação em zonas & $\begin{array}{l}\text { Sistemas geoambientais, } \\
\text { ecossistemas e formas de uso }\end{array}$ \\
\hline Potencial de biodiversidade & $\begin{array}{c}\text { Zonas de preservação com } \\
\text { proteção integral. } \\
\text { Remanescentes dos principais } \\
\text { componentes do ecossistema manguezal, } \\
\text { localmente representados } \\
\text { pelos canais estuarinos, } \\
\text { apicuns e bosque de manguezal. }\end{array}$ & $\begin{array}{l}\text { Setores do banco de algas } \\
\text { dos Cajuais, planície } \\
\text { hipersalina (apicum) e } \\
\text { bosque de manguezal. } \\
\text { Áreas relacionadas ao ninhal } \\
\text { das garças e de alimentação } \\
\text { das aves migratórias. }\end{array}$ \\
\hline $\begin{array}{l}\text { Zonas de uso sustentável } \\
\text { e relacionadas com usos } \\
\text { comunitários e soberania alimentar }\end{array}$ & $\begin{array}{l}\text { Setores onde as comunidades } \\
\text { realizam atividades extrativistas. } \\
\text { São as relacionadas aos } \\
\text { usos e com a retomada da } \\
\text { produtividade pesqueira; } \\
\text { setores com dinâmica sedimentar } \\
\text { para minimizar os efeitos } \\
\text { erosivos das ondas e marés; }\end{array}$ & $\begin{array}{c}\text { Sistemas ambientais relacionados } \\
\text { ao delta de maré e setores } \\
\text { do ecossistema manguezal } \\
\text { de usos comunitários } \\
\text { e ancestrais. } \\
\text { Setores utilizados para } \\
\text { a mariscagem, } \\
\text { pesca e captura de caranguejos. }\end{array}$ \\
\hline $\begin{array}{c}\text { Zonas de recuperação } \\
\text { ambiental }\end{array}$ & $\begin{array}{c}\text { Áreas degradadas através } \\
\text { das atividades de carcinicultura } \\
\text { e das salinas dentro do } \\
\text { ecossistema manguezal. } \\
\text { Locais de retomada das funções } \\
\text { ecológicas do ecossistema, } \\
\text { principalmente as relacionadas } \\
\text { com a ampliação do bosque de } \\
\text { manguezal para a produtividade } \\
\text { primária, captura de dióxido de } \\
\text { carbono e proteção da linha } \\
\text { de costa contra extremos climáticos. }\end{array}$ & $\begin{array}{l}\text { Planície de maré e ecossistema } \\
\text { manguezal. Áreas a serem } \\
\text { futuramente associadas à } \\
\text { preservação com a retomada } \\
\text { do bosque de manguezal. } \\
\text { Possíveis setores de pesca } \\
\text { e mariscagem devido potencial } \\
\text { de retomada da biodiversidade. }\end{array}$ \\
\hline Zonas de recrutamento & $\begin{array}{c}\text { Zonas especiais de manejo } \\
\text { integrado com as demais ações } \\
\text { de preservação, conservação } \\
\text { e recuperação } \\
\text { das áreas degradadas. } \\
\text { Está localizada no banco } \\
\text { de algas e regida pelas } \\
\text { ondas e as correntes marinhas. }\end{array}$ & $\begin{array}{l}\text { Delta de maré e planície de maré; } \\
\text { banco de algas dos Cajuais } \\
\text { e ecossistema manguezal. } \\
\text { Unidades ambientais de domínio } \\
\text { dos fluxos marinhos e do aquífero } \\
\text { (lençol freático associado aos } \\
\text { terraços marinhos), } \\
\text { da produtividade pesqueira } \\
\text { e para alimentação do peixe-boi } \\
\text { marinho e aves migratórias. . }\end{array}$ \\
\hline
\end{tabular}

Fonte: Elaboração própria. 
mais atividades de pesca, produção salineira e carcinicultura. Para orientar a definição das zonas foram utilizados resultados de pesquisas fundamentadas em abordagem sistêmica (RODRIGUEZ; VICENTE SILVA 2013; MEIRELES, 2014b) e com a integração dos processos geoambientais realizada através da evolução dos componentes costeiros associados aos efeitos eustáticos (origem da paleofalésia, dos terraços marinhos e dos dois setores emerso e submerso do banco de algas dos Cajuais).

\section{RESULTADOS E DISCUSSÃO}

O estuário Barra Grande compreende um complexo estuarino com extensão longitudinal de cerca de $3 \mathrm{Km}^{2}$ no sentido SE-NW, uma pequena parte coberta por manguezal e com os demais componentes representados pelos canais de maré, gamboas (canis de maré internos ao ecossistema manguezal), terraços marinhos, flechas de areia, faixa de praia vinculada ao delta de maré (MEIRELES, 2001) (Figura 2). O aporte de água doce para o manguezal é proveniente da laguna dos Cajuais que se interconecta ao manguezal, principalmente nos meses de maiores eventos pluviométricos. Há registros de resquícios de vegetação de mangue em uma planície aberta que sequencia o manguezal da Barra Grande, atualmente ocupada por salinas (alcançando setores próximos ao sopé das paleofalésias), com a acentuada salinidade no solo e, nas bordas das salinas, vegetação de manguezal de pequeno porte. Os depósitos de paleomangue, evidenciando a ligação direta do manguezal com a laguna dos Cajuais (ou lagoa do Carapicu) ainda resguarda indicadores morfológicos (canais de maré soterrados) da entrada da água do mar para a referida laguna.

A laguna dos Cajuais atualmente não é mais influenciada pela ação das marés (comportas regulam a entrada das marés e a saída de água doce). Entretanto atua como importante sistema que proporciona água doce para a hidrodinâmica proveniente dos fluxos de água vinculados ao sistema lacustre e ao aquífero localmente direcionados para o ecossistema manguezal.

O lençol freático, nos eventos de maior precipitação (primeiro semestre) aflora originando lagoas nas bordas do manguezal. Dessa forma, o aporte de água doce é sazonal. Nos setores topograficamente mais elevados com sedimentação arenosa, foi possível definir terraços marinhos holocênicos associados aos bosques de carnaúbas (Coprenicia prunifera). É importante evidenciar que a contribuição de água doce é também relacionada com surgências do aquífero na planície hipersalina (apicum) e no interior do bosque de manguezal (localmente
Figura 2: Componentes morfológicos de parte da planície costeira de Icapuí, evidenciando o setor central caracterizado pelo estuário e o banco de algas dos Cajuais (delta de maré), inseridos na APA da Barra Grande.

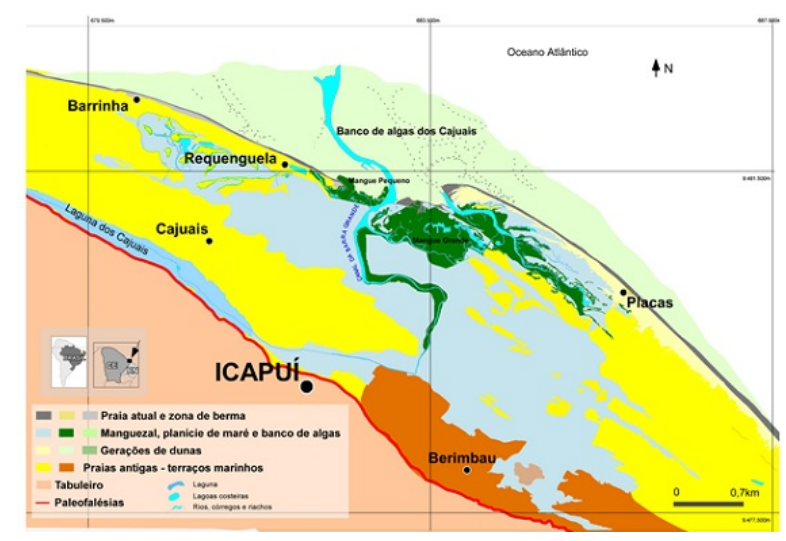

Fonte: Elaborada pelos autores.

chamados de "olheiros"). Esses pontos de ressurgência foram soterrados pelas obras de engenharia para a construção as piscinas dos criatórios de camarão e para a produção salineira.

As marés são o principal mecanismo de penetração das águas salinas nos manguezais. Essas inundações periódicas tornam o substrato favorável à colonização pela vegetação de mangue, isso porque excluem plantas que não possuem mecanismos de adaptação para suportar a presença de sal (SPALDING; KAINUMA. 2010). Em áreas onde as marés estão retomando seu domínio espacial (salinas abandonadas), foi identificada a retomada da vegetação de mangue. Foi também possível determinar que o setor central da planície costeira, principalmente nos sistemas morfológicos relacionados com as oscilações diárias das marés (planície hipersalina e delta de maré) apresentaram um dinamismo contínuo relacionado com a deriva das flechas e bancos de areia na desembocadura do canal estuarino. Durante as atividades de campo e através de diferentes recobrimentos de imagens de satélite, definiu-se que essas morfologias estão promovendo alterações no interior do canal e ao longo das praias (com setores erosivos e deposicionais). As gamboas (canais de maré com vegetação) localizadas no setor localmente denominada do Mangue Alto (porte arbóreo), determinou-se alterações batimétricas dos canais evidenciando retomada do fluxo sedimentar (de poucos centímetros para mais de $1,0 \mathrm{~m}$ de profundidade).

O manguezal da Barra Grande é caracterizado pela variação espacial das marés que imprime a deriva lito- 
rânea dos sedimentos ao longo da linha de costa. A formação das barras longitudinais de areia e os depósitos de sedimentos marinhos ocorreram nas porções leste e oeste do estuário, evidenciando comportamento dinâmico relacionado à sazonalidade no aporte de materiais sedimentares e a redistribuição de areia para o interior do delta de maré (bancos de areia ortogonais à deriva sedimentar devido ao fluxo estuarino). Ressalta-se que a dinâmica sedimentar das flechas de areia que migram de leste para oeste, é em função dos ventos alísios e da deriva litorânea (conjunção entre a direção preferencial dos ventos, as ondas, variações das marés e a fisiografia da linha de costa). Essa dinâmica sedimentar modificou acentuadamente a fisionomia da desembocadura do estuário: diante do delta de maré, nos últimos três anos, foi possível registrar o avanço da flecha de areia do setor leste do manguezal (praia da Placa) para oeste em mais de 1,0 km sobre o canal denominado de Manguinho (canal de maré interligado ao canal principal do estuário Barra Grande), modificando seu curso natural. Esta dinâmica natural das flechas de areia, durante a evolução deste setor da planície costeira, foi provavelmente relacionada a ciclos de fechamento e de rompimento dos depósitos sedimentares diante da desembocadura do canal estuarino Barra Grande (MEIRELES, 2014a). Desta forma, foram gerados pulsos espasmódicos de sedimentos durante os eventos processuais de ruptura das flechas de areia na direção do delta de maré. A caracterização espaçotemporal da migração recente das flechas de areia na desembocadura do estuário, constatou a possibilidade da dinâmica praial estar vinculada aos processos eustáticos (principalmente durante o último estágio glacial e o nível atual do mar) e, dessa forma, a construção dos depósitos relacionados aos terraços marinhos holocênicos e pleistocênicos. A evolução espaçotemporal (aplicação de algoritmos através do DSAS/ArqGis), foi necessária para evidenciar aspectos dinâmicos quantitativos e assim dimensionar as zonas ambientais também utilizando critério vinculado aos aspectos erosivos e deposicionais ao longo da linha de costa (Figura 3) (SOUZA, 2016, SOUZA et al., 2016).

Esse acúmulo de areia foi acrescido de biodetritos e argilas possivelmente relacionados aos eventos eustáticos e a sequência de rompimentos dos canais quando fechados pela dinâmica das flechas de areia (ebb canals) (CACHO et al., 1999, MONTREUIL et al., 2014). A concentração das barras de sedimentos diante do canal estuarino evidenciou a primazia da dinâmica nos canais, no sistema praial e campo de dunas na evolução morfológica do delta de maré. Constatou-se relações desses processos dinâmicos para a origem do delta de maré
Figura 3: Evolução da linha de costa evidenciando trechos erosivos (faixa de praia) e com acreção sedimentar (flecha de areia). Dinâmica atual possivelmente correlata aos processos morfológicos de abertura e fechamento do canal estuarino (com os espasmos de sedimentos direcionados para o delta de maré), durante os últimos eventos eustáticos.

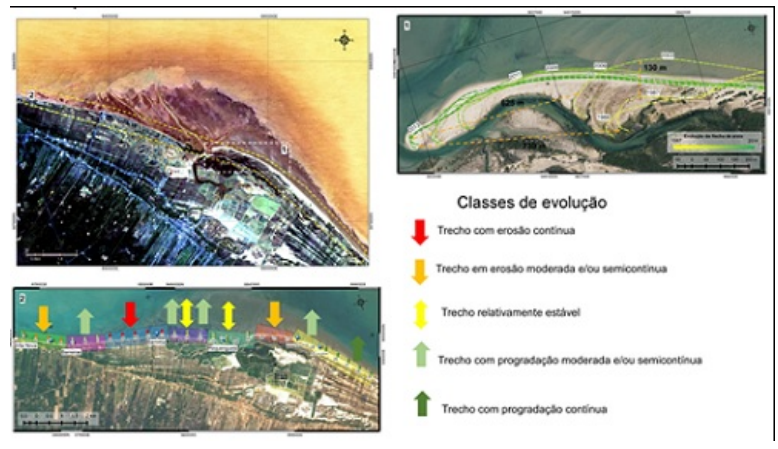

Fonte: (SOUZA 2016)

e vinculados com a fisiografia da linha de costa, mudanças do nível relativo do mar e processos neotectônicos que influenciaram na deriva litorânea na desembocadura do estuário (MEIRELES; SERRA; THIERS. 2006). As flechas e os bancos de areia na desembocadura do estuário delimitam o início do banco de algas (delta de maré).

No interior do estuário, setores com o predomínio de sedimentos lodosos foram aterrados por sedimentos arenosos que sufocaram as raízes do bosque de manguezal, levando à morte de parte da vegetação arbórea (predominantemente mangue vermelho Rhizophora mangle). Em outros locais identificou-se remoção de sedimentos nas proximidades do canal principal, desestabilizando as raízes do mangue e provocando erosão em áreas de expansão da cobertura vegetal. Devido à complexidade do transporte de areia e argila nos canais estuarinos também foi possível identificar a deposição de sedimentos sobre as raízes do bosque de mangue. O processo de sedimentação dá origem a um solo escuro, com elevado teor de sais, pobre em oxigênio e pouco compacto (PERILLIO, 1995), correlato ao identificado na Barra Grande onde, além disso, apresentou uma área deposicional de sedimentos arenosos nas margens do canal e vinculada à deriva litorânea na faixa de praia.

O manguezal da Barra Grande grada lateralmente para o banco de algas dos Cajuais (delta de maré) através de uma flecha de areia entre os canais de maré e a plataforma continental. Na faixa interna da flecha identificou-se a predominância de sedimentos limoargilosos e, no setor mais proximal da faixa de praia e 
o banco de algas os sedimentos são predominantemente arenosos com biodetritos e restos de algas.

Os terraços marinhos existentes na área evidenciaram os níveis de flutuação do mar durante o Quaternário e representam morfologias preponderantes na configuração atual da paisagem costeira em estudo. Desta forma, foi possível evidenciar o conjunto morfológico como resultado de uma relação entre os processos passados e os atuais de evolução geológica do litoral (MEIRELES, et al., 2005). A integração dos aspectos morfológicos da planície costeira proposta por Meireles e Campos (2010), através dos fluxos de matéria e energia, evidenciou a síntese de uma abordagem sistêmica (processos geoambientais e ecológicos) e a diversidade de usos identificada em escala local e associada ao setor central da planície costeira de Icapuí.

Os terraços marinhos se estendem desde a faixa mais periférica do manguezal (contato com o banco de algas), até o sopé da paleofalésia e, em conjunto com o delta de maré, as dunas mais interiores e as falésias, formam os indicadores morfológicos, geológicos, topográficos e sedimentológicos de antigos níveis de flutuações do mar (MEIRELES; SERRA; THIERS, 2006; CARTER; HESP; NODSTROM, 1997; KOCUREK; EWING, 2005). Nestes locais ocorreram registros de camadas de conchas (antigos níveis de praia) sobrepostas com níveis de deposição diferenciados (possivelmente mobilizações sedimentares provocadas pela ação dos ventos). Sobre os terraços marinhos também foram identificadas dunas de pequeno porte cobertas por gramíneas e herbáceas, em alguns locais com a presença de mangue ratinho (Conocarpus erectus).

A paleofalésia mantem conexão direta com o estuário através dos fluxos de sedimentos (transporte pluvial) e das energias gravitacional (deslizamentos e desmoronamentos) e a hidráulica direcionadas para o canal estuarino. Na base da paleofalésia foi constatada a ocorrência de nascentes de água doce (exutórios do lençol freático), que contribuem com água doce direcionada ao estuário pela laguna dos Cajuais (entre a paleofalésia o os terraços marinhos holocênicos).

A ocorrência de um sistema lagunar (lagoa dos Cajuais ou do Carapicu), ao conter registros sedimentológicos relacionados com as oscilações do nível relativo do mar e principalmente sobre mudanças climáticas durante o Holocêno, evidenciou o conjunto morfológico vinculado aos eventos eustáticos (em associação com a paleofalésia e os terraços marinhos).

Estes componentes geoambientais do estuário da Barra Grande estão inseridos na Área de Proteção Ambiental do Manguezal da Barra Grande e do Banco de
Algas dos Cajuais (APA) e conectam-se formando um mosaico de unidades de conservação (Figura 4) de importância ecológica, social, econômica e ambiental para a zona costeira cearense. A integração entre os componentes geoambientais, as formas de uso e ocupação e os impactos ambientais, foram sistematizado para dar consistência ao zoneamento ambiental com vista à gestão integrada da zona costeira e, especialmente, à unidade de conservação de uso sustentável (APA da Barra Grande).

\subsection{Zoneamento ambiental}

O zoneamento ambiental foi uma etapa fundamental para o processo de gestão da UC. Como elemento estruturante das atividades relacionadas à definição dos usos e para orientar as propostas de licenciamento ambiental, foi definido um elenco de unidades que culminou com a caracterização de 8 zonas (Figura 5). Ressaltase a efetiva participação do Comitê Gestor da APA da Barra Grande, com representantes dos segmentos da sociedade civil e do poder público municipal (atuando de forma deliberativa e com constituição paritária), na emissão de anuências de projeto executivos (mesmo sem a existência do Plano de Manejo e das zonas da APA estabelecidas através de equipe interdisciplinar).

Figura 4: Conjunto de Unidades de Conservação e proposta de corredores ecológicos.

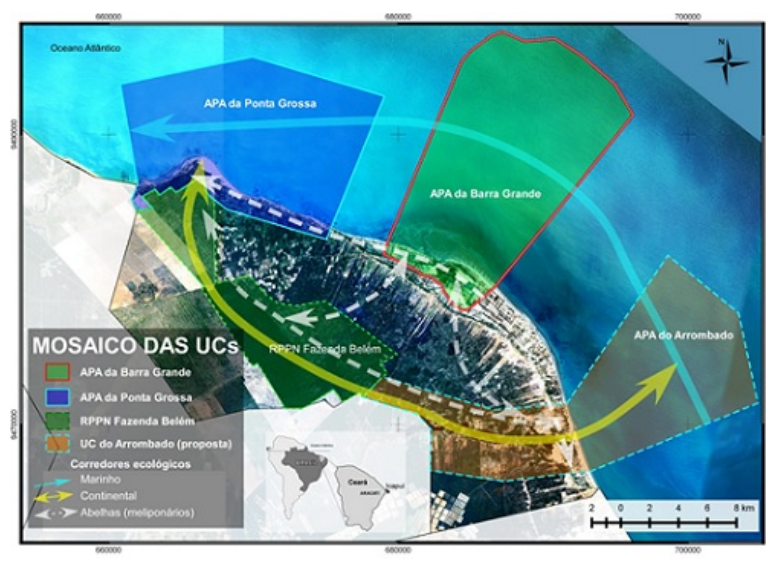

Fonte: Elaborada pelos autores.

Para contribuir com o processo de gestão através da proposição das zonas ambientais foi necessário definir os impactos ambientais (Figura 6). A recuperação dos setores degradados - principalmente pelas atividades salineira e carcinicultura - representa atividade fundamental para a efetividade das funções ecológicas 
e socioambientais da APA e a implantação das zonas de gestão para, essencialmente, potencializar as funções da APA relacionadas com a biodiversidade (retomada da produtividade pesqueira) e a retomada da produtividade primária para minimizar efeitos da sobrepesca (LIMA. 2007).

Foi possível identificar que as salinas em áreas antes de domínio do bosque de manguezal, foram a principal forma de degradação dos componentes do sistema estuarino Barra Grande. Provocaram interferências relacionadas com a modificação da estrutura pedológica do solo após o desmatamento, alterações nos canais de maré para a construção dos tanques de evaporação; concentração de sais em superfície da planície hipersalina impedindo a retomada da cobertura vegetal, além da perda de biodiversidade com a supressão do bosque de manguezal. Os fluxos hidrológicos provenientes da lagoa dos Cajuais e do aquífero (zona de exutório entre os terraços marinhos e a paleofalésia) e os vinculados às oscilações das marés, foram alterados através das obras de engenharia para a produção salineira. Aliado ao impacto das salinas está a criação de camarão em cativeiro (carcinicultura) (QUEIROZ et al. 2013) concentrada no setor mais à leste da planície de maré e que provocaram alterações na dinâmica estuarina e nos demais componentes ambientais em contato com os terraços marinhos.

Figura 5: Principais impactos ambientais relacionados com o sistema estuarino Barra Grande.

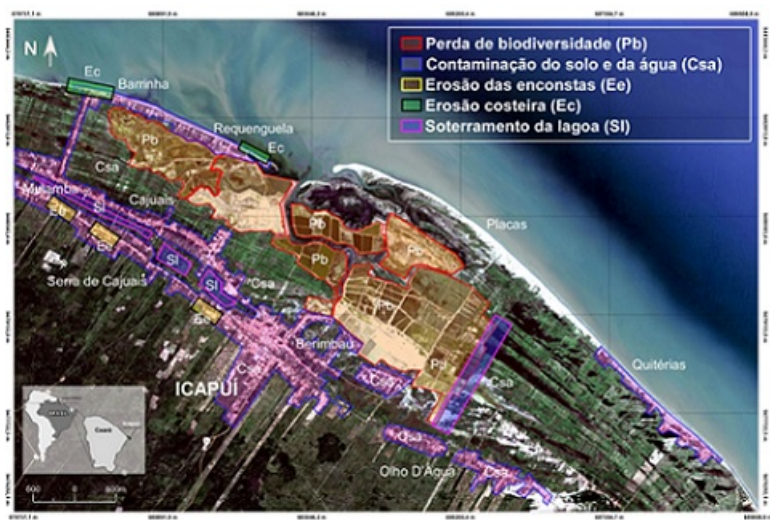

Fonte: Elaborada pelos autores.

A descrição das zonas identificadas foi de acordo com os parâmetros utilizados para a caracterização dos componentes morfológicos e vinculada às intervenções humanas nos fluxos de matéria e energia. Dessa forma, foram relacionados os aspectos geoambientais e ecodinâmicos do sistema costeiro, os quais fundamentaram os critérios para a definição das diversas zonas estabelecidas Os indicadores relacionados com o potencial de biodiversidade, uso sustentável e relacionadas com as atividades comunitárias e soberania alimentar, recuperação ambiental e recrutamento foram agrupadas de modo a inserirem-se nas zonas delimitadas em uma proposta de pré-zoneamento ambiental (modificado de AQUASIS, 2014) (Figura 5).

Figura 6: Mapa da APA da Barra Grande com proposta prézoneamento.

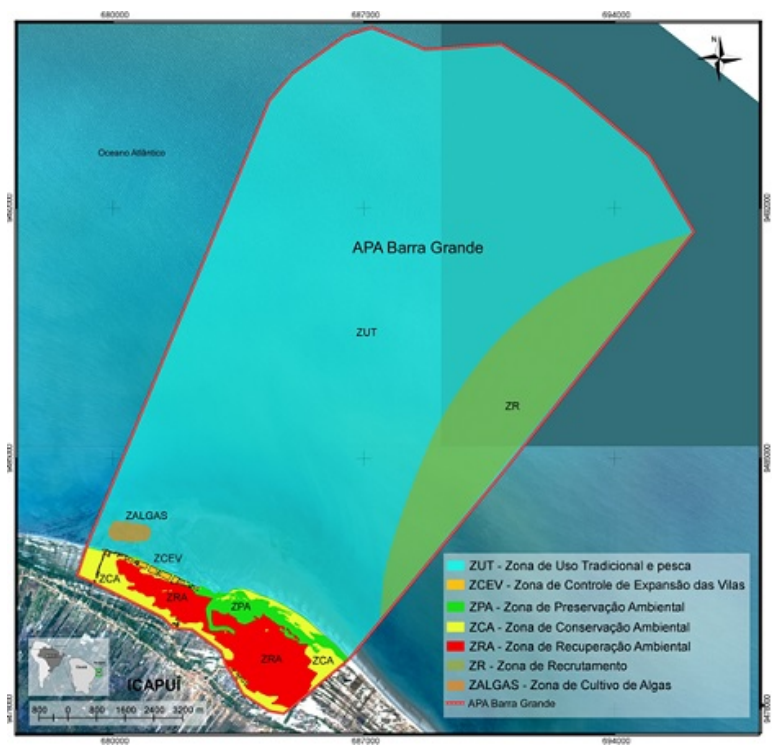

Fonte: Elaborada pelos autores.

- Zona de Preservação Ambiental (ZPA): Mangue Alto: localizada entre três canais de maré: da Barra Grande, Manguinho e Buraco da Nega. Há densa presença de mangue vermelho (Rhizophora mangle); as árvores apresentaram porte arbóreo até $8 \mathrm{~m}$ de altura. Na porção central aparece um apicum (planície hipersalina sem cobertura vegetal arbórea) com significativa extensão e em contato com o bosque de manguezal, canais de maré e a referida flecha de areia. Nesta proposta de zoneamento deverá ser destinada à pesquisa científica e preservação das espécies. Zona para a obtenção de propágulos utilizados na recuperação de áreas desmatadas e degradadas pelas fazendas de camarão e a exploração de sal marinho. Mangue Pequeno compreende uma faixa de mangue que se estende da Barra Grande até a comunidade do Requenguela. Representa o setor de interferência direta da Estação Ambiental Mangue Pequeno, onde fo- 
ram instalados os equipamentos como o Centro de Referência, viveiro de mudas, passarela de acesso ao manguezal e o observatório da vida marinha. A ZPA é também composta por setores onde estão sendo efetivadas a recuperação do ecossistema manguezal (replantio) e as atividades de educação ambiental e trilhas ecológicas.

- Zona de Uso Tradicional (pesca, mariscagem, catadores de caranguejos) (ZUT): Banco de Algas e Delta de Maré - O banco de algas dos Cajuais por proporcionar a base dos recursos pesqueiros e importante papel na regulação da biodiversidade e recrutamento de espécies. Trata-se da principal fonte de alimento para as comunidades tradicionais locais com atividades extrativistas relacionadas à coleta e cultivo de algas, pesca e mariscagem. Zona destinada ao conjunto de atividades extrativistas de coleta de mariscos, pesca artesanal, currais de pesca e cultivo de algas marinhas. A gestão das atividades tradicionais deverá vincularse aos processos dinâmicos imposto pela sazonalidade das ondas e marés, aos períodos de estiagem e chuvoso e aos ciclos das aves migratórias.

- Zona de Recuperação Ambiental (ZRA) Salinas Nazaré e Jassal e Fazendas de Camarão corresponde os sistemas ambientais degradado pelas salinas (uma área degradada com aproximadamente 382,7 hectares) e demais atividades de uso e ocupação em setores de domínio das marés com uma área total de 720,0 hectares. A salina Nazaré está inserida diretamente no ecossistema manguezal (englobando também canais de maré e apicum). Sugere-se a desativação dos cristalizadores de sal que estão em APP e o reestabelecimento do fluxo hidrológico para potencializar a retomada do bosque de manguezal (reflorestamento dos setores vinculados ao ecossistema manguezal). A carcinicultura deu sequência à degradação iniciada pelas salinas e ocupa uma área de 73,9 hectares. Os danos ambientais foram relacionados, cumulativamente, com a perda de biodiversidade, alterações na hidrodinâmica dos canais de maré e, possivelmente, interferências na produtividade pesqueira e incremento de processos erosivos (MEIRELES; CAMPOS, 2010). Sugere-se a desapropriação destas áreas localizadas em domínio das marés e que fazem parte da APP (ecossistema manguezal) para a aplicação de técnicas de reflorestamento e retomada das trocas laterais entre os terraços marinhos, o delta de maré, os campos de dunas e as paleofalésias (potencializar os fluxos de água doce provenientes dos aquíferos). Ações diretame4nte relacionadas à gestão adequado dos sistemas ambientais que promovem a produtividade pesquisa (AQUASIS, 2003).

- Zona de Conservação Ambiental (ZCA)Pilão compreende uma faixa de água represada pela salina Nazaré, utilizada como reserva para abastecimento dos cristalizadores para a utilização pública e atividades de lazer e práticas esportivas. A área alagada apresenta boa qualidade para a prática de esportes náuticos, caminhadas e exercícios físicos.

- Zona de Controle de Expansão das Vilas ZCEV - Zona de Controle da Expansão das Vilas - está inserida nos terraços marinhos. As comunidades localizadas nas proximidades da linha de costa estão associadas diretamente associada à ZCA e ZUT. As comunidades mais interiores também evidenciaram um modo de vida extrativista e de relação direta com a biodiversidade que emana do ecossistema manguezal e do bando de algas dos Cajuais. Foi definida de modo a evidenciar a gestão especial das comunidades tradicionais de pescadores, marisqueiras e catadores de caranguejos inseridas dentro da APA da Barra Grande. As ocupações existentes e as planejadas (a serem licenciadas com anuência do conselho do meio ambiente e do comitê gestor), deverão evidenciar baixos índices de impermeabilização (definidos com o plano diretor do município, conselho municipal do meio ambiente e comitê gestor), saneamento básico e arborização utilizando plantas nativas. As intervenções deverão levar em conta a dinâmica ecológica dos demais ecossistemas e da biodiversidade associada (aves migratórias, peixe-boi marinho e atividades de pesca, coleta de caranguejos, mariscagem e cultivo de algas).

- Zona de Recrutamento (ZR) - Zona de Recrutamento de biodiversidade - setor relacionado com a dinâmica das correntes marinhas (recrutamento, dispersão e disseminação das espécies para o interior da APA e banco de macroalgas), associada ao setor leste e disposto no sentido norte-sul da área marinha representada pelo banco de algas dos cajuais. As atividades de pesca e mariscagem deverão ser inibidas para a manutenção e a ampliação da biodiversidade. As atividades de pesquisa e monitoramento deverão ser realizadas por equipe interdisciplinar com a participação direta dos pescadores, algicultores e marisqueiras. 
- Zona de Cultivo de Algas (ZALGAS) - trata-se de uma zona de expansão do cultivo de algas localizado diante da comunidade da Barrinha e a aproximadamente $1,5 \mathrm{~km}$ à nordeste da linha de costa. As práticas comunitárias de cultivo deverão ser potencializadas de modo a reverter as práticas de coleta intensiva de algas (LIMA; CARNEIRO; MEIRELES, 2014). Além de atuar como áreas de recrutamento e atratores de biodiversidade.

As sete zonas propostas foram definidas de modo a potencializar os sistemas ambientais de acordo com os indicadores propostos e relacionados, principalmente, com a melhoria da produtividade pesquisa e da biodiversidade. Dessa forma, e diante da abordagem interdisciplinar em sistemas ambientais de elevada complexidade e fragilidade ambiental, setores com graves problemas ambientais relacionados com a indústria salineira e a carcinicultura, deverão ser prioritários. É fundamental a participação popular no planejamento e gestão da UC, haja vista que, esta é uma ferramenta essencial no processo de conservação, levando em conta a mobilização social já existente no município de Icapuí.

\section{CONSIDERAÇÕES FINAIS}

Conforme o exposto pode-se concluir a importância ambiental da APA da Barra Grande para o município de Icapuí, considerando sua complexidade e conexão com os diversos sistemas ambientais da zona costeira, tendo o manguezal como vínculo entre os fluxos de matéria e energia e as diversas formas de uso e ocupação. Um conjunto de componentes relacionados diretamente à cadeia reprodutiva, à soberania alimentar das comunidades tradicionais de pescadores e marisqueiras e demais funções socioambientais que impulsionam a diversidade socioeconômica e cultural.

As unidades geoambientais que compõem a planície costeira de Icapuí foram analisadas de modo a definir a dinâmica morfológica associada aos eventos eustáticos. A integração dos processos ambientais foi realizada tomando como base a disponibilidade e a energias de transporte de sedimentos e nutrientes, fácies sedimentares e componentes morfológicos associados.

Desta forma, e com a diversidade de informações sistematizadas neste estudo, foi possível colaborar enfatizando a necessidade de retomada das políticas ambientais locais para a gestão da APA. A proposta de zoneamento ambiental foi estruturada de modo a evidenciar abordagens inter e multidisciplinares e, dessa forma, atuar como base das discussões nas etapas relacionadas com a participação popular e das entidades da sociedade civil, para a confecção do plano de manejo. As diversas formas de uso foram delimitadas em $7 \mathrm{zo}-$ nas específicas para proporcionar a ordenação das ações com vistas à qualidade socioambiental.

As demais Unidades de Conservação existentes no entorno da APA da Barra Grande deverão ser indutoras de ações comunitárias e administrativas conjuntas para integrá-las através da instituição de um mosaico de unidades de conservação e dos corredores ecológicos.

\section{REFERÊNCIAS}

AQUASIS. Associação de Pesquisa e Preservação de Ecossistemas Aquáticos. A Zona Costeira do Ceará: diagnóstico para a gestão integrada. Fortaleza: AQUASIS, 2003. 248 p. Coordenadores: Alberto Alves Campos [et al.].

Associação de Pesquisa e Preservação de Ecossistemas Aquáticos. Diagnóstico ambiental e pré-zoneamento da APA da Barra Grande/IcapuíCE. Fortaleza: Mapas Temáticos e Pré-Zoneamento, 2014. 87 p. Relatório Técnico.

BRASIL. Lei no 9.985, de 18 de julho de 2000 . Institui o Sistema Nacional de Unidades de Conservação da Natureza (SNUC). 2000.

CACHO, I.; GRIMALT, J. O.; PELEJERO, C.; CANALS, M.; SIERRO, F. J.; FLORES, J. A.; SHACK-LETON, N. J. Dansgaard-oeschger and heinrich event imprints in alboran sea temperatures. Paleoceanography 14, p. 698-705, 1999.

CARTER, R. W. G.; HESP, P. A.; NODSTROM, K. F. Erosional landforms in coastal dunes. Ed. by Nordstrom, K.F.; Psuty, N. \& Carter. Bill; Coastal dune - from and process, p. 217-250, 1997.

CEARÁ. Prefeitura Municipal de Icapuí. Lei Municipal no 298, 12 de maio de 2000. Institui a Área de Proteção Ambiental da Barra Grande. 2000.

Prefeitura Municipal de Icapuí. Lei Municipal $n^{0}$ 634, 25 de fevereiro de 2014. Costeira do Ceará: diagnóstico para a gestão integrada. Coordenadores: Alberto Alves. 2014.

DIEGUES, A. C. Ecologia Humana e Planejamento em Áreas Costeiras. 2. ed. São Paulo: NUPAUB, 2001. v. 1. 225 p. 
ÁREA DE PROTEÇÃO AMBIENTAL (APA) DA BARRA GRANDE EM ICAPUÍ-CE: CAMINHOS PARA A SUSTENTABILIDADE

KOCUREK, G.; EWING, R. C. Aeolian dune field self-organization - implications for the formation of simple versus complex dune-field patterns. Geomorphology, v. 72, p. 94-105, 2005.

LIMA, A. P. S.; CARNEIRO, R. N.; MEIRELES, A. J. A. Ecossistema banco de algas e identidade territorial no município de icapuí/ce: comunidade tradicional pesqueira e meio técnico-científico-informacional. Revista Eletrônica do PRODEMA Fortaleza, Brasil, v. 8, n. 2, p. 35-49, 2014.

LIMA, M. C. Pescadoras e pescadores artesanais do ceará: modo de vida, confrontos e horizontes. Mercator, v. 10, p. 39-54, 2007.

MEIRELES, A. J. A. Geomorfologia costeira: funções ambientais e sociais. 2. ed. Fortaleza: Edicões UFC, 2014. 489 p.

Methodological bases and criteria for environmental licensing in conservation units from sabiaguaba, fortaleza, brazil. Mercator (Fortaleza. Online), v. 13, p. 139-158, 2014.

MEIRELES, A. J. A.; CAMPOS, A. A. Componentes geomorfológicos, funções e serviços ambientais de complexos estuarinos no nordeste do brasil. Revista da ANPEGE, v. 6, p. 89-107, 2010.

MEIRELES, A. J. A.; RUBIO, R. P. Geomorfologia litoral: una propuesta metodológica sistémica en la llanura costera de ceará, nordeste de brasil. Revista de Geografía (Barcelona), Universidad de Barcelona, v. 33, p. 165-182, 1999.

MEIRELES, A. J. A.; SANTOS, A. M. F. Evolução geomorfológica da planície costeira de icapuí, extremo leste do ceará, nordeste do brasil. Geografia (Rio Claro. Impresso), v. 36, p. 519-534, 2011.

MEIRELES, A. J. A.; SERRA, J. R.; THIERS, P. R. L. Aspectos geodinâmicos do delta de maré da planície costeira de icapuí/ce. In: Borzacciello, J.S., Dantas, E.W. e MEIRELES, A.J.A. Litoral e Sertão - Natureza e Sociedade no Nordeste Brasileiro. Fortaleza: Expressão gráfica, 2006. v. 1, p. 367-382.

MENEZES, G. V. Recuperação de Manguezais: um estudo de caso na Baixada Santista, Estado de São Paulo, Brasil. Tese (Doutorado) — USP, São Paulo, 1999.

MONTREUIL, A. L.; LEVOY, F.; BRETEL, P.; ANTHONY, E. Morphological diversity and complex sediment recirculation on the ebb delta of a macrotidal inlet (normandy, france): A multiple lidar dataset approach. Geomorphology, v. 219, p. 114-125, 2014.

NOVELLI, Y. S. Grupos de Ecossistemas: marisma, manguezal e apicum. Santos-SP: [s.n.], 1995.

QUEIROZ, L. S.; ROSSI, S.; MEIRELES, A. J. A.; COELHO, C. Shrimp aquaculture in the federal state of ceará, 1970e2012: Trends after mangrove forest privatization in brazil. Ocean \& Coastal Management, v. 73, p. 54-62, 2013.

RODRIGUEZ, J. M. M.; VICENTE SILVA, E. Planejamento e Gestão Ambiental: Subsídios da Geoecologia das Paisagens e da Teoria Geossistêmica. 1. ed. Fortaleza: Edicões UFC, 2013. $370 \mathrm{p}$.

SILVA, E. V.; RODRIGUEZ, J. M. Planejamento e zoneamento de bacias hidrográficas: a geoecologia das paisagens como subsídio para uma gestão integrada. Caderno Prudentino de Geografia, p. 4-17, 2014.

SILVA, J. A.; MEIRELES, A. J. A. Manguezal da barra grande em icapuí-ce: Da degradação ao processo de recuperação e mudança de atitude. Anais do IX ENANPEGE, Goiânia-GO, 2011.

SOUZA, W. F. Sensoriamento remoto e SIG aplicados à análise da evolução espaçotemporal da linha de costa do município de Icapuí, Ceará. 210 p. Dissertação (Programa de Pós-Graduação em Geografia) - Universidade Federal do Ceará (UFC), 2016.

SOUZA, W. F.; LEITE, N. S.; MEIRELES, A. J. A.; SILVA, E. V. O uso de sig na análise da evolução de linha de costa controlada por promontório: trecho entre as praias de ponta grossa e retiro grande, icapuí-ceará. Revista da Casa da Geografia de Sobral, p. 20-35, 2016.

SPALDING, M. D.; KAINUMA, M. L. World Atlas of Mangroves. London: Earthscan, with International Society for Mangrove Ecosystems, Food and Agriculture Organization of the United Nations, UNEP World Conservation Monitoring Centre, 2010. Tehran: Roshd. (Original work published 1971). World Atlas of Mangroves. Earthscan, London, UK, 319 pp. 